\title{
Performance Studies on Stone Mastic Asphalt Mixes with Reclaimed Asphalt Pavement
}

\author{
Anusha T M, Akhilesh B R, H S Jagadeesh
}

\begin{abstract}
Stone mastic asphalt (SMA) is a gap graded mix which is categorised by more quantity of coarse aggregate, high asphalt content and fibre. Due to stone on stone contact and presences of high filler content, it acts as a stiff matrix and reduces the rutting due to heavy traffic load. This research presents a study on fatigue performance RAP replaced SMA mixes using VG 30 as binder along with elastomer as a modifier and results were compared with conventional SMA mix. The specimens prepared were tested using several laboratory test procedures: Marshall mix design, indirect tensile strength, moisture susceptibility, drain down test and Repeated load fatigue test. Test results showed Marshall Properties of the RAP mix improved up to a RAP content of $30 \%$ without elastomer modifier and RAP content up to $60 \%$ with elastomeric modifier. From the moisture susceptibility test results, the elastomeric modified SMA mix showed high resistance to moisture damage when compared to conventional mix and $30 \%$ RAP replacement mix. Repeated load fatigue test was conducted for different stress load and temperature and results showed elastomeric modified SMA mix offered high resistance to deformation across all stress level and temperature when compared to conventional and optimum RAP mix. As a fatigue loading increased resulted in decrease of number of fatigue cycles and increased in the initial tensile strain of the mix. As the percentage of RAP addition increased the initial tensile strain decreased.
\end{abstract}

Key words: Stone Mastic Asphalt, Indirect Tensile Strength, Reclaimed Asphalt Pavement, Repeated load Fatigue test, Resilient modulus,

\section{INTRODUCTION}

\section{A. General}

A good road network plays a vital role in the economy of a country. It provides access to remote places for various transport activities. Road network in India is about 5.9 million kilometre, which ranks place second in the world after United States. Stone Mastic Asphalt (SMA) is a gap graded Mix developed by Germans in late 1960s and it has been used for construction of roads in many countries like Germany, United States, United Kingdom, Australia, China etc. The SMA mix provides stone skeleton structure which is held together by a high binder content, which provides a high rut resistance bituminous course.

Manuscript received on October 05, 2021.

Revised Manuscript received on October 18, 2021.

Manuscript published on November 30, 2021.

* Correspondence Author

Anusha T M*, Ph.D. Student, Department of Civil Engineering, BMS College of Engineering, Bangalore (Karnataka), India.

Akhilesh B R, Department of Civil Engineering, BMS College of Engineering, Bangalore (Karnataka), India.

Dr H S Jagadeesh, Professor, Department of Civil Engineering, BMS College of Engineering, Bangalore (Karnataka), India.

(C) The Authors. Published by Blue Eyes Intelligence Engineering and Sciences Publication (BEIESP). This is an open access article under the CC BY-NC-ND license (http://creativecommons.org/licenses/by-nc-nd/4.0/)
SMA mix contains about $70-80 \%$ of coarse aggregates, 8$12 \%$ of filler, $6-7 \%$ of binder, $0.3 \%$ of fibres [1]. SMA mix may allow the binder and the aggregate dust to drain when the mixture is hot during storage, transporting and placement. To prevent the drain down stabilizing additive is added. The chemically treated conventional aggregates with virgin bitumen (VG 30) and modified (CRMB) with virgin aggregates can be used in gap graded mixes (SMA) to meet the drain down requirements as per norms. CRMB mixes provides higher performance, even though chemically treated aggregates mixes showed better moisture resistance properties in the mixes [2]. The coconut fiber can be used in SMA mixtures as a replacement for cellulose fiber to prevent asphalt drain down [3]. Commercial name of Elastomer modifier is VIATOP® plus FEP (Functional Elastomer Pellet), consisting of approx. 20\% arbocel fibre and $80 \%$ elastomeric additive. This type of pellets designed for HMA wearing courses of heavy traffic load roads, improving pavement performance through superior binder property. It improves stiffness of the mix while somewhat improving low temperature behaviour as well [4]. Reclaimed asphalt pavement (RAP) material is the output of milling of bituminous layers during pavement rehabilitation. The disposal of RAP materials takes a significant portion of landfill and leads to many environmental issues. RAP can be effectively used in the soil (sub-grade), sub-base and base of the flexible pavements which results in reduction of the construction cost and environmental issues [5]. The Properties of the hot mix asphalt (HMA) with RAP materials mainly depends on the properties of the RAP materials used, especially binder obtained from RAP. It is assumed that binder of RAP is usually stiffer when compared to neat bitumen, due to its aging process. Use of RAP materials stiffens the asphalt mix and contributes in improving the rut resistance of the mix. Analysis of wheel track test with comparison to binder properties shows that increasing amount of modified binder from RAP, occurs in increasing in rut resistance of asphalt mix [6]. Fatigue performance of the RAP mixes has been found to improve up to a RAP content of $35 \%$ when compared with virgin mixes [7]. Fatigue performance of asphalt plays vital role in the design and performance of highway and airport roads. However, developments in flexible pavement design indicates that fatigue cracking as the major distress in the pavements that directly influences the service life and quality of roads. Fatigue failure is caused by repeated traffic loading, which further results in crack propagation, crack initiation, and eventually leads to catastrophic failure of the pavement material due to unstable crack growth. Wide range of cracking in flexible pavements is common sight on $\mathrm{NH}$ (national highway) in India.

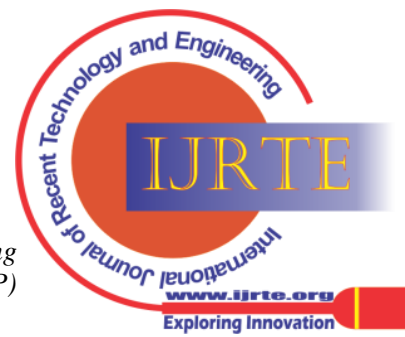


These cracks caused by fatigue will not only decreases the loading capacity of bituminous layers, but also allows water to percolate to the base and subgrade, thereby accelerating the distress in flexible pavement, if timely maintenance is not followed [8]. The effect of aggregate type plays an ensuring durability of flexible pavement. There is a good relationship exists between the texture and shape of fine aggregates and fatigue performance of the mix. Higher the thickness of the mix in flexible pavement structure, the shape and texture properties of aggregates will have more influence [9]. Beam fatigue tests and drain down tests indicated that increase in aggregate size in an aggregate gradation decreases fatigue life of a mix and increases binder drainage, respectively. The stiffer SMA mix has lower fatigue life and less rut resistant. It is found that with increase in aggregate size in an aggregate gradation, Rut resistance and mix stiffness also increased [10]. Along with aggregate type Mineral filler also plays an important role in SMA mix, they fill air voids and improve the cohesion of asphalt binder. The asphalt mix prepared with $80 / 100$ grade bitumen and stone dust as filler, yielded highest fatigue life of asphalt mix compared to cement and sand used as filler [11]. The mixing and compaction temperature will contribute to the fatigue life of pavement. Repeated Fatigue load test results shows the greater number of fatigue cycles and maximum modulus of resilient at optimum compaction temperature $140^{\circ} \mathrm{C}$ and mixing temperature $160^{\circ} \mathrm{C}$ [12]. Engineering properties of the SBS (Styrene Butadiene Styrene) modified mix show higher values to that of the conventional mix. Fatigue life of SBS modified mix increased from 2.1 to $2.4 \%$ compared to neat BC mix [13]. The glass fibres have the potential to resist structural distress like fatigue that occur in road pavement as result of increased traffic loading [14]. DBM mixes were modified with nano silica shows higher fatigue life among all the failure loading compared to conventional DBM mix. The DBM mix modified with $4 \%$ nano silica shows higher resilient modulus when compared to conventional bituminous mix [15].

\section{B. Objectives}

1. To evaluate the optimum binder content and the optimum RAP percentage in SMA mixes using Elastomer modifiers.

2. To study and to compare the Moisture Susceptibility of the conventional SMA mix and RAP replaced SMA mixes.

3. To determine the Fatigue life of conventional SMA mix, optimum RAP replaced SMA mix with and without elastomer modifier at different temperature and stress load level.

4. To establish the relationships between resilient modulus and Fatigue life cycles, Initial Tensile strain and Fatigue life cycles at different stress load level for SMA mix, RAP replaced SMA mix with and without elastomer modifier.

\section{Scope}

This study investigates the indirect tensile fatigue characteristics of conventional SMA mix, RAP replaced SMA mixes and RAP replaced modified SMA mixes with elastomer modifier for $10 \%, 20 \%$ and $30 \%$ of stress load obtained from ITS test. The loading frequency used for important role in the fatigue behaviour of asphalt mix for

entire study is $1 \mathrm{~Hz}$ (1cycle per second). The Marshall method of mix design used to find optimum binder and RAP content with and without elastomer modifier. ITS test has been carried out at room temperature for three types of mixes used in this study to fix up the stress levels for repeated load fatigue test. $5 \mathrm{~mm}$ deformation is kept as failure criteria. Relationship were established between resilient modulus and fatigue cycles and between initial tensile strain and fatigue cycles at different stress load level.

\section{LABORATORY INVESTIGATIONS}

\section{A. Aggregates}

The aggregates acts as the skeleton which transfers the load through the particle to particle contact. The aggregates of different gradation of sizes $20 \mathrm{~mm}, 12 \mathrm{~mm}, 6 \mathrm{~mm}$ down size and stone dust were procured from KMS crushers, Bagalur in Kolar District. The basic tests were performed, and the results were illustrated in the Table I, satisfying the MoRT\&H [16] requirements.

Table- I: Physical properties of Natural aggregates

\begin{tabular}{|l|c|c|}
\hline \multicolumn{1}{|c|}{ Properties tested } & Test results & $\begin{array}{c}\text { Specification as per } \\
500-35 \text { of MoRTH-5 }\end{array}$ \\
\hline Impact value & $17.51 \%$ & $<18 \%$ \\
\hline Crushing value & $23 \%$ & Not specified \\
\hline Los angeles abrasion value & $17.5 \%$ & $<25 \%$ \\
\hline Combined Flakiness \& & & $<30 \%$ \\
Elongation index & $10.51 \%$ & $<2 \%$ \\
\hline Water absorption value & $0.4 \%$ & Not specified \\
\hline Specific gravity & & \\
20mm & 2.68 & \\
$12 m m$ & 2.69 & \\
$6 m m$ & 2.71 & \\
Stone dust & 2.72 & \\
\hline
\end{tabular}

\section{B. Bitumen}

Bitumen of grade 60/70 (VG30) is used as binder in this research studies. At normal temperature they are in the form of semi-solid, it is heated until liquefied before it is blended with aggregates. The basic tests [17] were carried out and the results were illustrated in Table II.

Table- II: Physical properties of binder

\begin{tabular}{|l|c|c|}
\hline Properties & Test results & $\begin{array}{c}\text { Specification as per } \\
\text { IS 73:2013 }\end{array}$ \\
\hline $\begin{array}{l}\text { Penetration Test at } \\
25^{\circ} \mathrm{C}, 0.1 \mathrm{~mm}\end{array}$ & 64 & Min 45 \\
\hline $\begin{array}{l}\text { Softening Point } \\
\left({ }^{\circ} \mathrm{C}\right), \text { min }\end{array}$ & 48 & Min 47 \\
\hline $\begin{array}{l}\text { Ductility Test }(\mathrm{cm}) \\
\text { at } 25^{\circ} \mathrm{C}\end{array}$ & $100+$ & Min 40 \\
\hline Flash Point $\left({ }^{\circ} \mathrm{C}\right)$ & 240 & Min 220 \\
\hline Fire Point $\left({ }^{\circ} \mathrm{C}\right)$ & 284 & - \\
\hline Specific Gravity & 1.013 & $0.97-1.02$ \\
\hline
\end{tabular}

Published By:

Blue Eyes Intelligence Engineering 


\section{RAP}

Reclaimed Asphalt Pavement (RAP) materials are procured from NH-206, Gangavaram, which 15 years old pavement. The test results are tabulated in Table III.

Table- III: Physical properties of RAP

\begin{tabular}{|l|c|c|}
\hline \multicolumn{1}{|c|}{ Test } & Results & $\begin{array}{c}\text { Specification as } \\
\text { per 500-35 of } \\
\text { MoRTH-5 }\end{array}$ \\
\hline Impact Value & $9.73 \%$ & $<18 \%$ \\
\hline $\begin{array}{l}\text { Combined Flakiness } \\
\text { and Elongation Index }\end{array}$ & $22.68 \%$ & $<30 \%$ \\
\hline Aggregate crushing & $19.56 \%$ & $<30 \%$ \\
\hline $\begin{array}{l}\text { Specific } \\
\text { gravity }\end{array}$ & 2.66 & Not specified \\
\hline Water Absorption & $0.55 \%$ & $<2 \%$ \\
\hline
\end{tabular}

\section{Filler}

Bag house dust is used as mineral filler in this study. It is procured from S.L.V crushers, Periyapatna. The filler must be free from organic impurities and shall have plasticity index less than 4 .

\section{E. Stabilizer additive}

In this study cellulose fibres utilized as additive. The dosage should be minimum of $0.3 \%$ by the weight of mix.

Table- IV: Properties of Fibres used in SMA mix

\begin{tabular}{|l|c|}
\hline Content of ARBOCEL ZZ8/1 & $20 \%$ \\
\hline $\begin{array}{l}\text { Content of } \\
\text { functional Additive }\end{array}$ & $80 \%$ \\
\hline Color & $\begin{array}{c}\text { Grey cylindrical } \\
\text { pellets }\end{array}$ \\
\hline $\begin{array}{l}\text { Average pellet } \\
\text { length }\end{array}$ & $3 \mathrm{~mm}-20 \mathrm{~mm}$ \\
\hline $\begin{array}{l}\text { Average pellet } \\
\text { thickness }\end{array}$ & $3 \mathrm{~mm}-6 \mathrm{~mm}$ \\
\hline Bulk density & $280 \mathrm{~g} / \mathrm{l}-380 \mathrm{~g} / \mathrm{l}$ \\
\hline $\begin{array}{l}\text { Sieve analysis: finer } \\
\text { than 3.55mm }\end{array}$ & Max.8\% \\
\hline
\end{tabular}

\section{G. Bitumen modifier}

In this study VIATOP ${ }^{\circledR}$ plus FEP (Functional Elastomer Pellets) is used as bitumen modifier. It is grey cylindrical pellets, blended with $20 \%$ by weight cellulose fibers and $80 \%$ by weight functional additive. This modifier can be added in two method, dry process and wet process. In dry process, admixing of VIATOP ${ }^{\circledR}$ plus FEP is carried out together with the bitumen and aggregate mix in a laboratory asphalt mixer. Where in wet process admixing of modifier is carried out with hot bitumen. In wet process Elastomeric modified bitumen is prepared separately in the laboratory and it is mandatory to use proper stirring time, stirring intensity, and temperature to blend all components of the pellets homogeneously and effectively in the bitumen.

In this research work dry process of mixing method is adopted, where dried aggregate particles are heated up together with modifier to $170^{\circ} \mathrm{C}$ and mixed for 15 seconds with laboratory mixer at $170^{\circ} \mathrm{C}$. The hot bitumen is subsequently added and mixed for a further 105 seconds. Asphalt samples must be mixed until aggregate particles are properly covered and the asphalt mix appears to be homogeneous. Elastomer modifier and cellulose fiber are procured from "Strategic Marketing and Research Team" Bengaluru, India. The properties are tabulated in Table IV.

\section{H. Aggregate gradation}

The nominal aggregate sizes of $20 \mathrm{~mm}, 12 \mathrm{~mm}, 6 \mathrm{~mm}$ down size and stone dust were sieved as per the gradation of SMA mix for wearing course and should be within the limits as per MoRTH. The trial and error method was adopted to achieve gradation for SMA mixes. The proportion of aggregates obtained is $10 \%, 65 \%, 6 \%, 8 \%$, and $11 \%$ for $20 \mathrm{~mm}, 12 \mathrm{~mm}, 6 \mathrm{~mm}$, stone dust and filler respectively. Obtained gradation of aggregate as illustrated in Table V.

\section{Marshall mix design}

Once the gradation is fixed, SMA mix is designed using AASTHO MP8 standard specification for conventional, RAP replaced with and without elastomer modifier. The strength of the specimen is measured in terms of the Marshall Stability value which is defined as the maximum load sustained by a compacted specimen at a loading rate of $50.8 \mathrm{~mm} / \mathrm{min}$ [18-19].

Firstly, the conventional SMA mix is prepared with varying bitumen content starting from 5.75\%, 6\%, 6.25\%, 6.5\% and $6.75 \%$. The optimum binder content is obtained. In the next stage, to determine the optimum RAP in the SMA mix, RAP is replaced in the range of $10 \%, 20 \%, 30 \%, 40 \%$ and $50 \%$. $0.3 \%$ of cellulose fibre and is added in the SMA mix. Addition of elastomer modifier in a SMA mixes is at a quantity of $15 \%$ of the weight of bitumen. The addition of elastomer modified can added by dry process (mixed with aggregates). Here RAP is replaced in the range of $30 \%$, $40 \%, 50 \%, 60 \%, 70 \%$ and $80 \%$. For conventional SMA mix, the results shows highest Marshall Stability value of $8.4 \mathrm{kN}$, flow values are between $2-4 \mathrm{~mm}$ and the maximum air voids of $4 \%$ is observed at OBC of $6 \%$. The Optimum Binder Content (OBC) obtained is 6\%. Optimum RAP obtained is $30 \%$. For $30 \%$ RAP replacement maximum stability value is $13.02 \mathrm{kN}$. With the use of elastomer modifier in the mix, optimum RAP is increased up to $60 \%$. For $60 \%$ RAP addition maximum stability is $9.39 \mathrm{kN}$. Other Marshall properties are within the limit of MoRTH. The results were tabulated in Table VI.

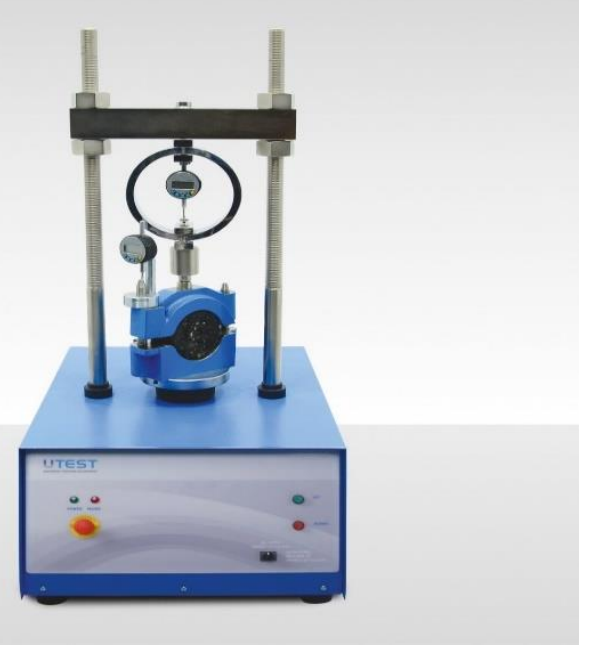

Fig. 1: Marshall testing apparatus

Published By:

Blue Eyes Intelligence Engineering and Sciences Publication (BEIESP) (C) Copyright: All rights reserved. 


\section{Performance Studies on Stone Mastic Asphalt Mixes with Reclaimed Asphalt Pavement}

\section{J. Drain down}

The fines and bitumen that separates and flows out from the bituminous mix during storage and transportation is called drain down of the bituminous mix. The drain down of the loose SMA mix is determined according to IRC: SP: 792008 [1]. The test was performed at the anticipated plant production temperature for uncompact SMA mix and maximum allowable drain down for SMA mix is $0.30 \%$. The test apparatus consists of a wire basket with the sieve opening size of $6.3 \mathrm{~mm}$. The wire basket along with the mix is kept in the oven for an hour that is maintained at a temperature of $120^{\circ} \mathrm{C}$ to $175^{\circ} \mathrm{C}$. The drain down test results were tabulated in table 7 . The equation is as follows,

Draindown $(\%)=((\mathrm{D}-\mathrm{C}) /(\mathrm{B}-\mathrm{A})) * \mathbf{1 0 0} \quad \ldots$ (1)

Where, A is the mass of the empty wire basket (gm), B is the mass of the wire basket plus sample (gm), $\mathrm{C}$ is the mass of the empty catch plate (gm), D is the mass of the catch plate plus drained material (gm).

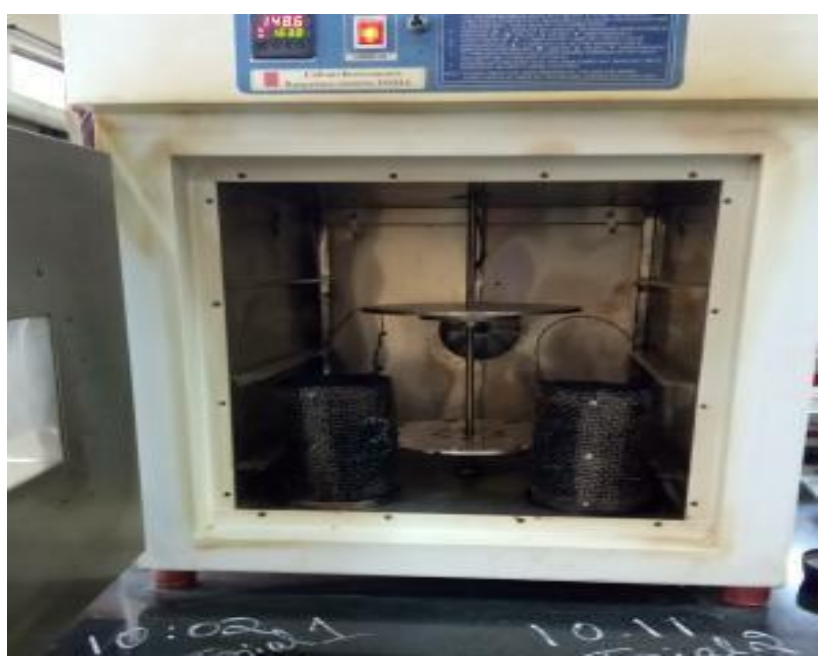

Fig. 2: Drain down test apparatus

The drain down test yielded good results for all type of mix. It is found that drain down is least for RAP replaced SMA mix with elastomer modifier and other mixes were found to be $0.3 \%$ which is within in the limits as prescribed in MoRTH. The results of drain down were tabulated in Table VII.
Table- V: Gradation of SMA mix

\begin{tabular}{|c|c|c|}
\hline $\begin{array}{l}\text { Sieve size } \\
(\mathrm{mm})\end{array}$ & $\begin{array}{l}\text { Desired gradation } \\
\text { (\%) }\end{array}$ & $\begin{array}{l}\text { Obtained gradation } \\
\text { (\%) }\end{array}$ \\
\hline 26.5 & 100 & 100 \\
\hline 19 & 100 & 100 \\
\hline 13.2 & $100-90$ & 96.875 \\
\hline 9.5 & $75-75$ & 69.85 \\
\hline 4.75 & $28-20$ & 22.868 \\
\hline 2.36 & $24-16$ & 17.772 \\
\hline 1.18 & $24-13$ & 16.404 \\
\hline 0.6 & $18-12$ & 15.744 \\
\hline 0.3 & $20-10$ & 14.182 \\
\hline 0.075 & $12-8$ & 11.552 \\
\hline
\end{tabular}

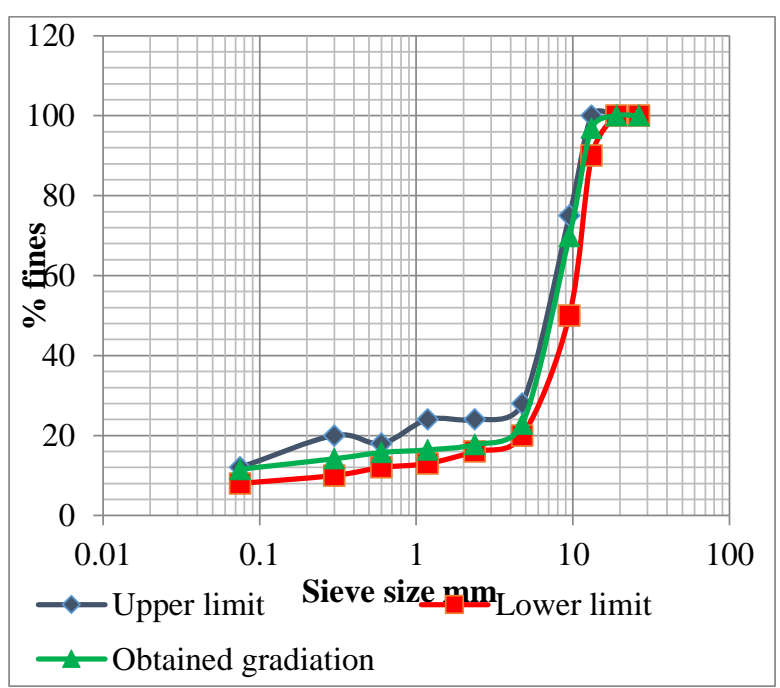

Fig. 3: Obtained gradation of SMA mix

Table- VI: Drain down values of different SMA mix

\begin{tabular}{|c|c|}
\hline Type of SMA mix & Drain down (\%) \\
\hline Conventional SMA mix & 0.019 \\
\hline SMA mix with optimum RAP & 0.022 \\
\hline SMA mix with RAP and Bitumen modifier & 0.015 \\
\hline
\end{tabular}

Table- VII: Marshall Properties of SMA mix

\begin{tabular}{|c|c|c|c|c|c|c|}
\hline & $\begin{array}{c}\text { Marshall } \\
\text { stability (KN) }\end{array}$ & $\begin{array}{c}\text { Flow value } \\
(\mathrm{mm})\end{array}$ & $\begin{array}{c}\text { Unit weight } \\
(\mathrm{g} / \mathrm{cc})\end{array}$ & Air void (\%) & VMA (\%) & VFB (\%) \\
\hline $\begin{array}{c}\text { Conventional } \\
\text { SMA mix }\end{array}$ & 8.403 & 3.080 & 2.359 & 4.03 & 76.480 \\
\hline 30\% RAP replaced SMA mix & 13.023 & 4.043 & 2.353 & 4.02 & 17.07 & 76.472 \\
\hline $\begin{array}{c}\text { 60\% RAP replaced SMA mix } \\
\text { with modifier }\end{array}$ & 9.390 & 4.023 & 2.389 & 4.15 & 76.167 \\
\hline
\end{tabular}

\section{K. Moisture susceptibility and indirect tensile strength}

Moisture susceptibility is done in order to know the ability of SMA mix to resist the moisture damage. The test was conducted for conventional SMA mix, 30\% RAP replaced SMA mix and 60\% RAP replaced SMA mix with elastomer modifier. Around 6 samples were prepared, 3 samples were tested for conditioned and 3 were tested for controlled. The compaction of the specimen should be so, that it should have
Published By:

Blue Eyes Intelligence Engineering and Sciences Publication (BEIESP) (C) Copyright: All rights reserved. air voids $7 \pm 0.5 \%$. Here conditioned samples were subjected to freeze-thaw cycle. Then specimens are tested for ITS as per ASTM D4123 [20]. The TSR (Tensile Strength Ratio) for SMA mix should be minimum $85 \%$ [1].

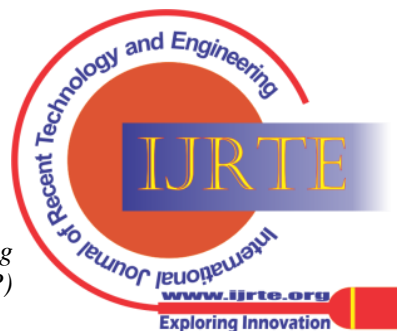


From the ITS, moisture susceptibility test results it was found that the SMA mix with optimized RAP with elastomer modifier (i.e. 60\% RAP) have high resistance to moisture damage than conventional SMA mix and optimized RAP (i.e. 30\% of RAP) without elastomer modifier. The results were tabulated in Table VIII.

\section{Repeated load fatigue test}

The repeated loading fatigue test is an indirect tensile test carried on a cylindrical bituminous specimen by repeating compressive loading along the vertical diametrical plane in a half sine wave pattern. The test is conducted for conventional SMA mix, RAP replaced SMA mixes modified with elastomer for stress level of $10 \%, 20 \%$ and $30 \%$ of failure load which is obtained from ITS test.

The equipment is as shown in figure 4 consists of LVDT (Linear variable differential transducer), loading frame, data acquisition system with a loading rate capacity up to 5 tonnes loading piston and position controller. Application of load is applied over the prepared specimen using 2 stainless steel plates. As the sample starts deforming further horizontal and vertical deformation of the sample were measured using two sets of LVDT's (i.e. 4no). The reading are recorded for the applied load, deflection of both horizontal and vertical LVDT's for each cycle and the total number of repetitions before failure is noted for each individual test was done by a data acquisition system. In the present research study, below mentioned test parameter was adopted such as frequency of $1 \mathrm{~Hz}$ (1 cycle per second), failure deformation of $5 \mathrm{~mm}$, pressure fixed approximately around 30-35 Pascals. The following expressions from Kennedy (1978), were used to evaluate the resilient modulus and initial tensile strain values from the data obtained from the fatigue test. The resilient modulus is calculated using,

$\mathrm{Mr}=\mathbf{P}^{*}(\mathbf{0 . 2 7}+\mu \mathrm{r}) /\left(\mathrm{Hr}^{*} \mathbf{h}\right)$

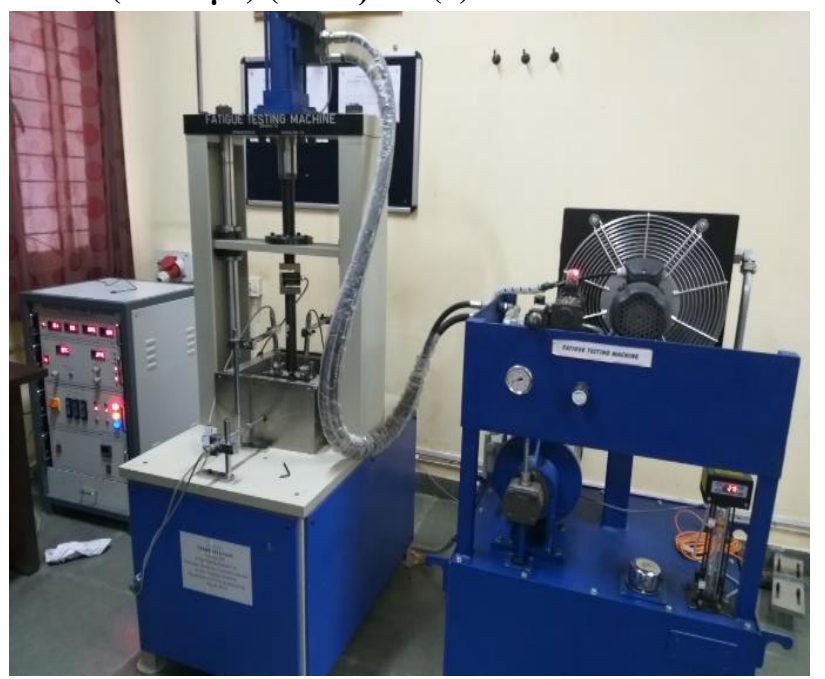

Fig. 4: Repeated load fatigue test apparatus

Table-VII: Indirect tensile strength test results

\begin{tabular}{|c|c|c|c|}
\hline Mix & $\begin{array}{c}\text { Stability of unconditioned } \\
\text { specimen }(\mathrm{kN})\end{array}$ & $\begin{array}{c}\text { Stability of conditioned } \\
\text { specimen at } 60^{\circ} \mathrm{C}(\mathrm{kN})\end{array}$ & 316.75 \\
\hline Conventional SMA mix & 365.92 & 613.21 & 86.56 \\
\hline SMA mix with optimum RAP & 675.68 & 658.76 \\
\hline Optimum RAP with elastomer modifier & 703.22 & 93.68 \\
\hline
\end{tabular}

Initial tensile strain,

$\varepsilon=\sigma \max (1+3 \mu r) / M r \quad \ldots .(5)$

The maximum horizontal tensile stress is calculated using,

$\sigma \max =2 P / \pi \mathrm{dt} \ldots . .(6)$

Where, $\mu \mathrm{r}=$ Instantaneous Resilient Poisson's ratio, $\mathrm{Hr}=$ average horizontal deformation in $\mathrm{mm}, \mathrm{Vr}=$ average vertical deformation in $\mathrm{mm}, \mathrm{Mr}=$ Resilient Modulus of Elasticity (MPa), $\mathrm{P}=$ applied load in $\mathrm{N}, \mathrm{h}=$ height of specimen in $\mathrm{mm}, \mathrm{d}=$ diameter of specimen in $\mathrm{mm}, \mathrm{t}=$ thickness of specimen in $\mathrm{mm}$

\section{RESULTS AND DISCUSSION}

\section{A. Repeated load Fatigue test}

Effect of elastomer modifier on Fatigue life of SMA mix: The Fatigue Test was conducted for conventional SMA mix, RAP replaced SMA mix with and without elastomer modifier at $10 \%, 20 \%$, and $30 \%$ failure load of Indirect Tensile Strength Test at $25^{\circ} \mathrm{C}, 35^{\circ} \mathrm{C}$ and $45^{\circ} \mathrm{C}$ temperature. The fatigue life is found to be more for the RAP with elastomer modified SMA mix, for all the combination of stress load and temperature when compared to other mixes. As the stress load increases the fatigue life of the mix will decreases. At higher temperature the fatigue life of the mix will be less. At $25^{\circ} \mathrm{C}$ temperature the number of fatigue

cycles for conventional mix is found to be 5015, 1245 and 327 for $10 \%, 20 \%$ and $30 \%$ stress load respectively. Similarly for optimum RAP of $30 \%$ the fatigue cycles were found to be 9680, 3223 and 714 for 10\%, 20\% and 30\% stress load respectively. For optimum RAP of $60 \%$ with elastomer modifier 18136, 6180 and 1628 for $10 \%$, 20\% and $30 \%$ stress load respectively. At $35^{\circ} \mathrm{C}$ temperature the number of fatigue cycles for conventional mix is found to be 2461, 617 and 282 for 10\%, 20\% and 30\% stress load respectively. Similarly for optimum RAP of $30 \%$ the fatigue cycles were found to be 4417, 970 and 160 for 10\%, 20\% and $30 \%$ stress load respectively. For optimum RAP of $60 \%$ with elastomer modifier 9170, 2445 and 515 for $10 \%$, 20\% and $30 \%$ stress load respectively. At $45^{\circ} \mathrm{C}$ temperature the number of fatigue cycles for conventional mix is found to be 1820, 272 and 145 for 10\%, 20\% and 30\% stress load respectively. Similarly for optimum RAP of $30 \%$ the fatigue cycles were found to be 1352, 410 and 180 for $10 \%, 20 \%$ and $30 \%$ stress load respectively. For optimum RAP of $60 \%$ with elastomer modifier 3854, 1180 and 345 for 10\%, 20\% and $30 \%$ stress load respectively.

Published By:

Blue Eyes Intelligence Engineering and Sciences Publication (BEIESP) (C) Copyright: All rights reserved.

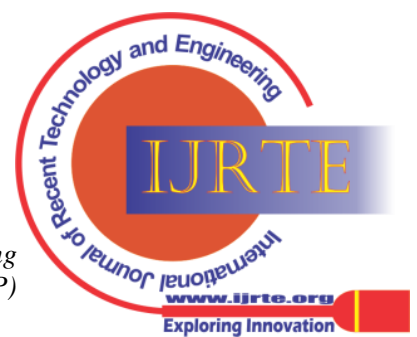




\section{Performance Studies on Stone Mastic Asphalt Mixes with Reclaimed Asphalt Pavement}

Table- IX: Results of repeated load fatigue test at $25^{\circ} \mathrm{C}$

\begin{tabular}{|c|c|c|c|}
\hline $\begin{array}{c}\text { Stress level } \\
\text { (\% of } \\
\text { failure } \\
\text { load) }\end{array}$ & $\begin{array}{c}\text { Number of } \\
\text { repitions to } \\
\text { failure }\end{array}$ & $\begin{array}{c}\text { Mr } \\
\text { (Mpa) }\end{array}$ & $\begin{array}{l}\text { Initial tensile } \\
\text { strain (micro- } \\
\text { strain) }\end{array}$ \\
\hline \multicolumn{4}{|c|}{ For conventional at $25^{\circ} \mathrm{C}$ temp. } \\
\hline 10 & 5015 & 3172.2062 & 386.642422 \\
\hline 20 & 1245 & 4667.8713 & 393.583751 \\
\hline 30 & 327 & 4730.8038 & 435.749739 \\
\hline \multicolumn{4}{|c|}{ For $30 \%$ RAP at $25^{\circ} \mathrm{c}$ temp. } \\
\hline 10 & 9680 & 3510.198 & 291.246736 \\
\hline 20 & 3223 & 5529.7191 & 342.704122 \\
\hline 30 & 714 & 9460.0093 & 377.906358 \\
\hline \multicolumn{4}{|c|}{ For $60 \%$ RAP with elastomer modifier at $25^{\circ} \mathrm{C}$ temp. } \\
\hline 10 & 18136 & 5129.478 & 251.338294 \\
\hline 20 & 6180 & 8362.8474 & 328.72894 \\
\hline 30 & 1628 & 6365.3397 & 417.10139 \\
\hline
\end{tabular}

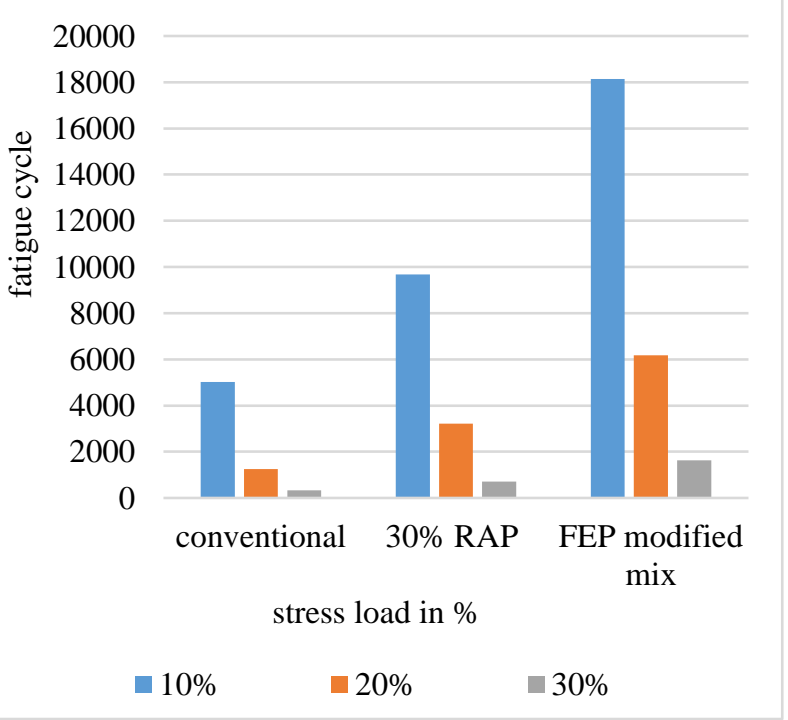

Fig. 5: variation of fatigue life with stress level at $25^{\circ} \mathrm{C}$ temperature

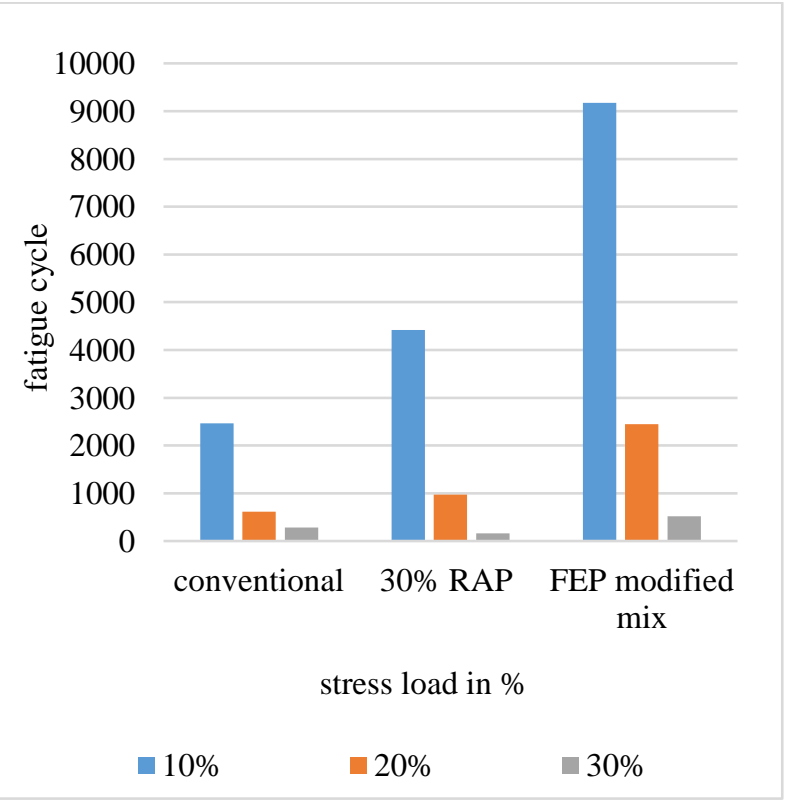

Fig. 6: Variation of fatigue life with stress level at $35^{\circ} \mathrm{C}$ temperature

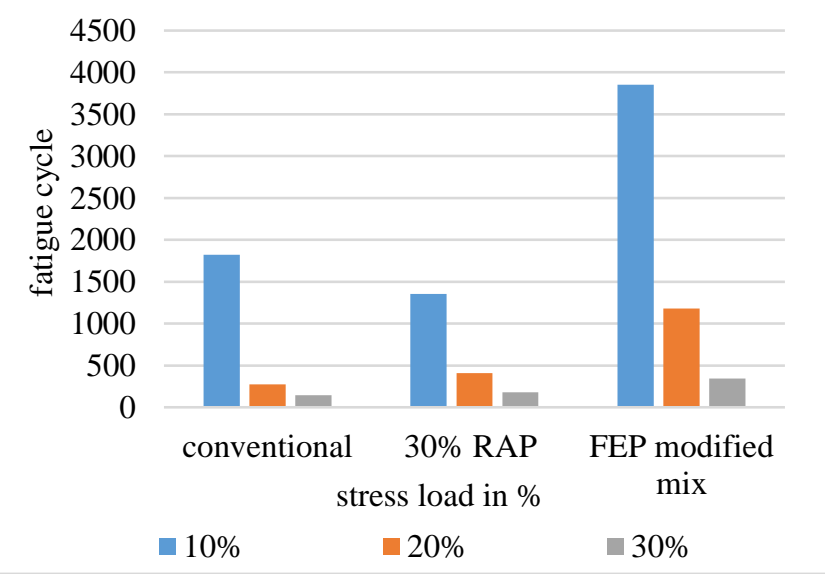

Fig. 7: Variation of fatigue life with stress level at $45^{\circ} \mathrm{c}$ temperature

Variation of fatigue life with resilient modulus and initial tensile strain in SMA mix, RAP replaced with and without elastomer modifier: The resilient modulus and initial tensile strain were calculated using equation $4 \& 5$. As the fatigue cycle increases the initial tensile strain also increases but resilient modulus decreases. As the stress load applied increases both resilient modulus and initial tensile strain increases.

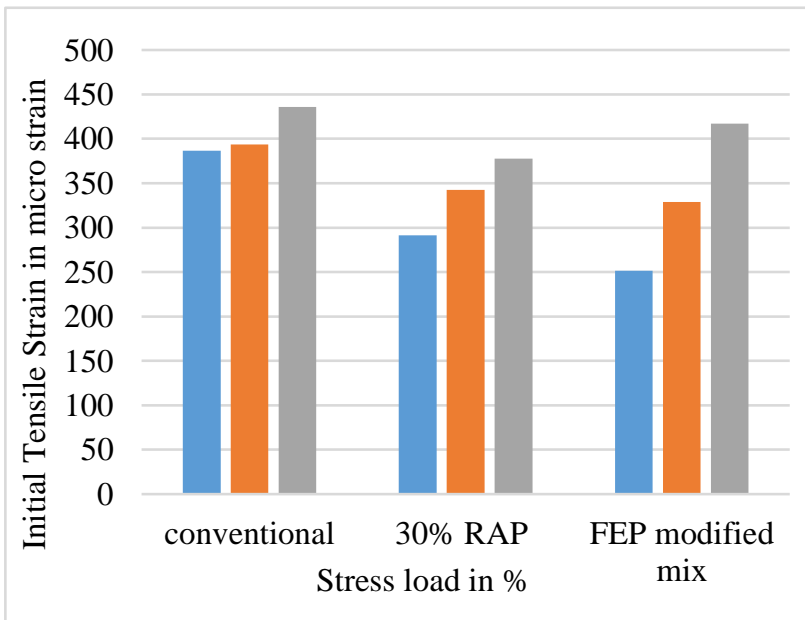

घ $10 \%$ stress level $\square 20 \%$ stress level $\square 30 \%$ stress level

Fig. 8: Variation of Initial tensile strain with stress level at $25^{\circ} \mathrm{c}$ temperature

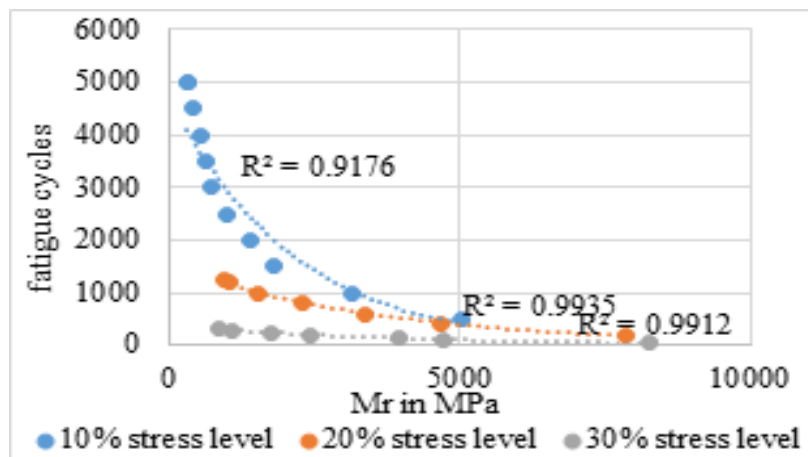

Fig. 9: Fatigue cycle V/S Mr for conventional at $25^{\circ} \mathrm{C}$ temperature

Published By:

Blue Eyes Intelligence Engineering and Sciences Publication (BEIESP) (C) Copyright: All rights reserved.

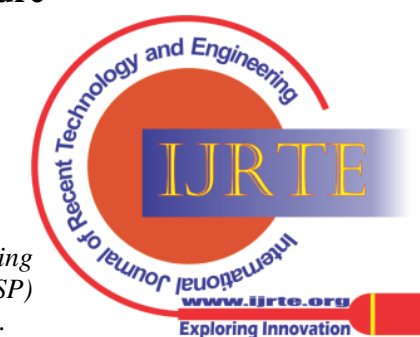




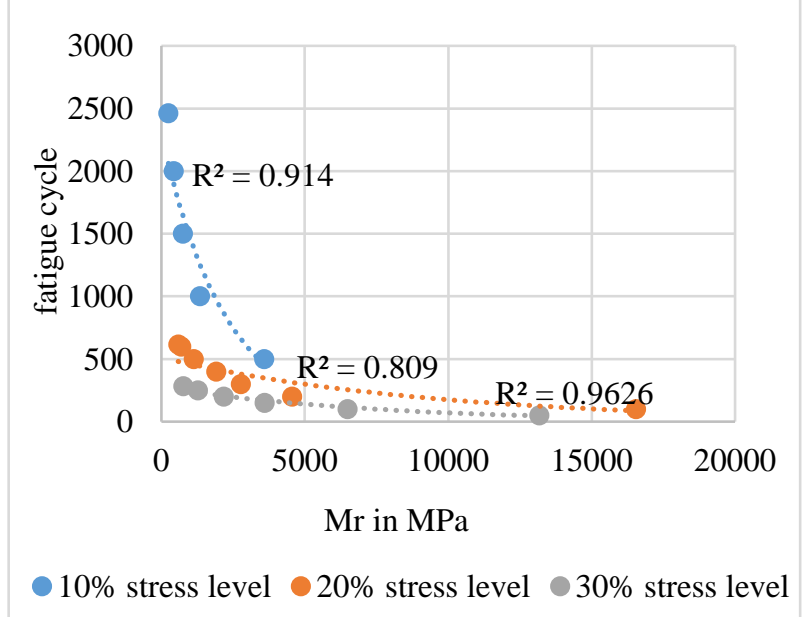

Fig. 10: Fatigue cycle V/S Mr for conventional at $35^{\circ} \mathrm{C}$ temperature

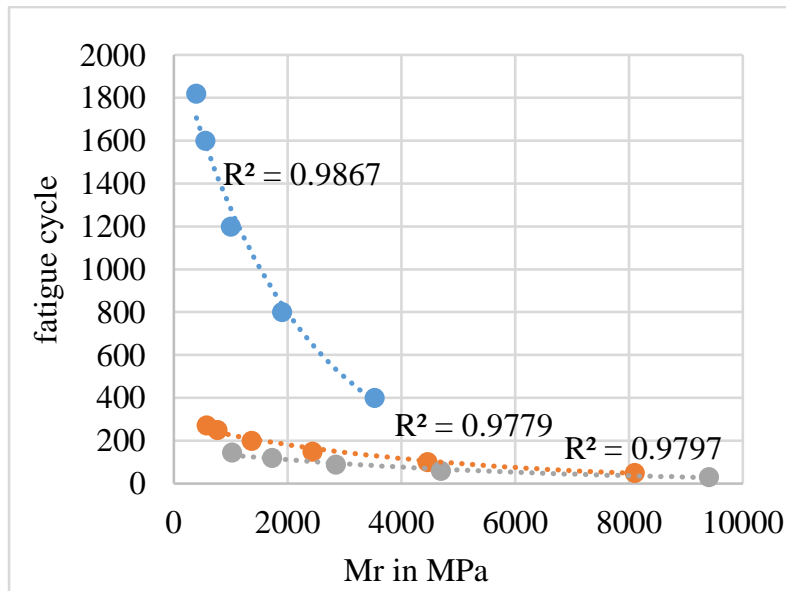

-10\% stress level $\bullet 20 \%$ stress level $\bullet 30 \%$ stress level

Fig. 11: Fatigue cycle V/S Mr for conventional at $45^{\circ} \mathrm{C}$ temperature

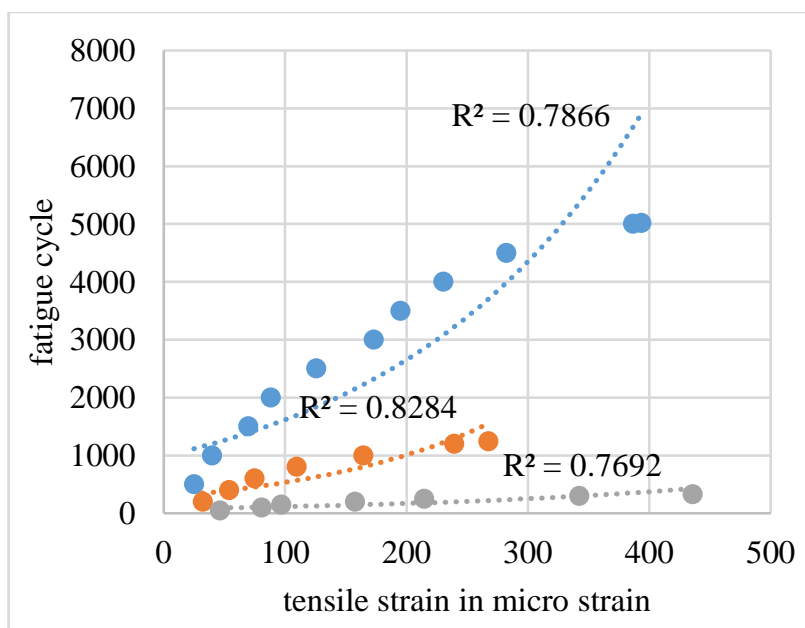

- $10 \%$ stress level $\quad 20 \%$ stress level $\quad 30 \%$ stress level

Fig. 12: Fatigue cycle V/S initial tensile strain for conventional at $25^{\circ} \mathrm{c}$ temperature

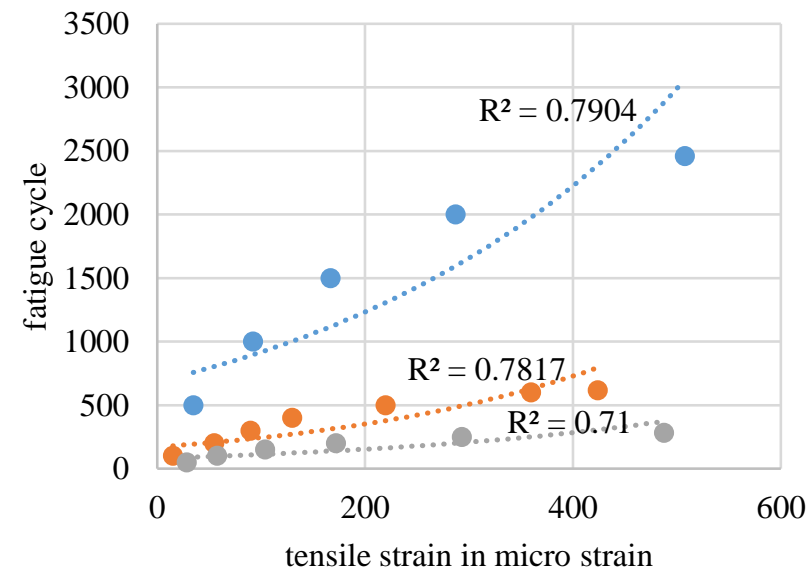

$10 \%$ stress level $20 \%$ stress level $30 \%$ stress level

Fig. 13: Fatigue cycle V/S initial tensile strain for conventional at $35^{\circ} \mathrm{C}$ temperature

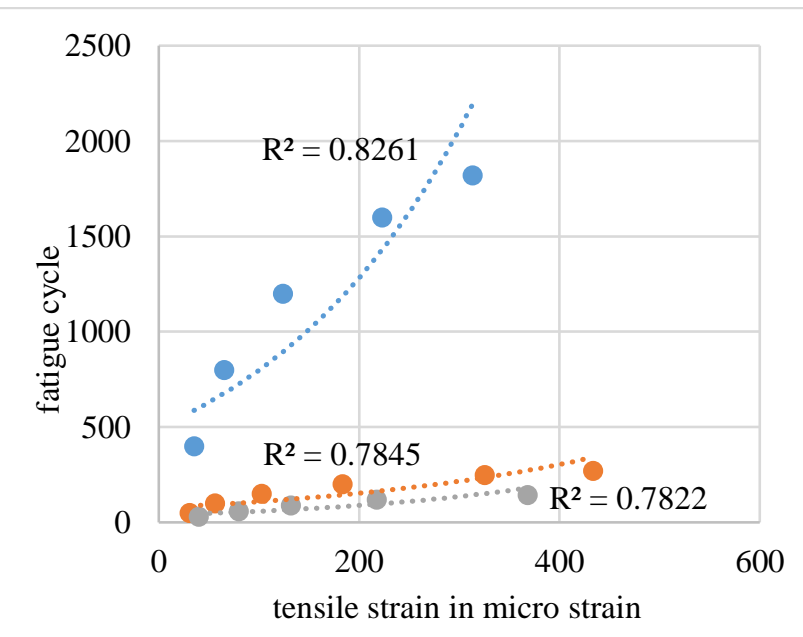

- $10 \%$ stress level $20 \%$ stress level $\quad 30 \%$ stress level

Fig. 14: Fatigue cycle V/S initial tensile strain for conventional at $45^{\circ} \mathrm{C}$ temperature

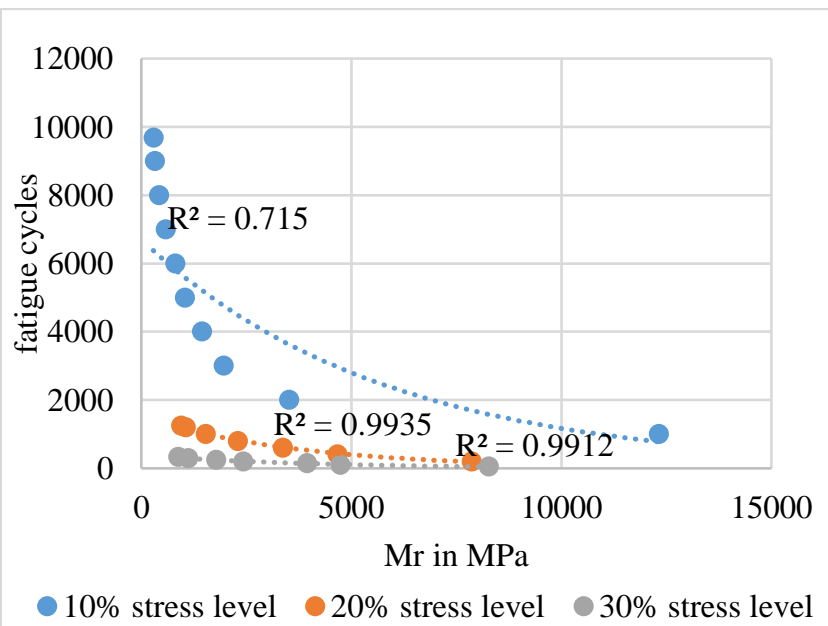

Fig. 15: Fatigue cycle V/S Mr for $30 \%$ RAP at $25^{\circ} \mathrm{C}$ temperature

Published By:

Blue Eyes Intelligence Engineering and Sciences Publication (BEIESP) (C) Copyright: All rights reserved. 
Performance Studies on Stone Mastic Asphalt Mixes with Reclaimed Asphalt Pavement

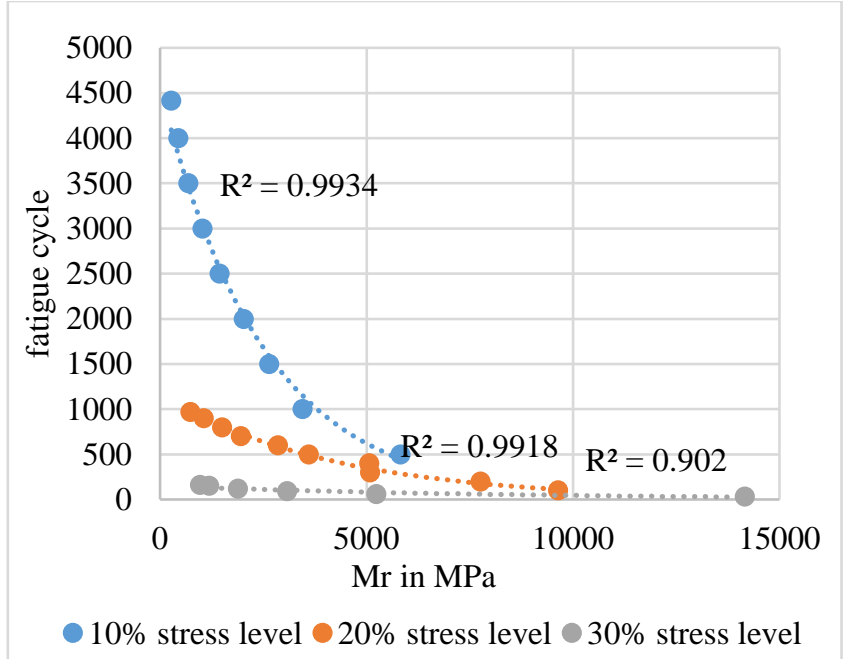

Fig. 16: Fatigue cycle V/S Mr for $30 \%$ RAP at $35^{\circ} \mathrm{C}$ temperature

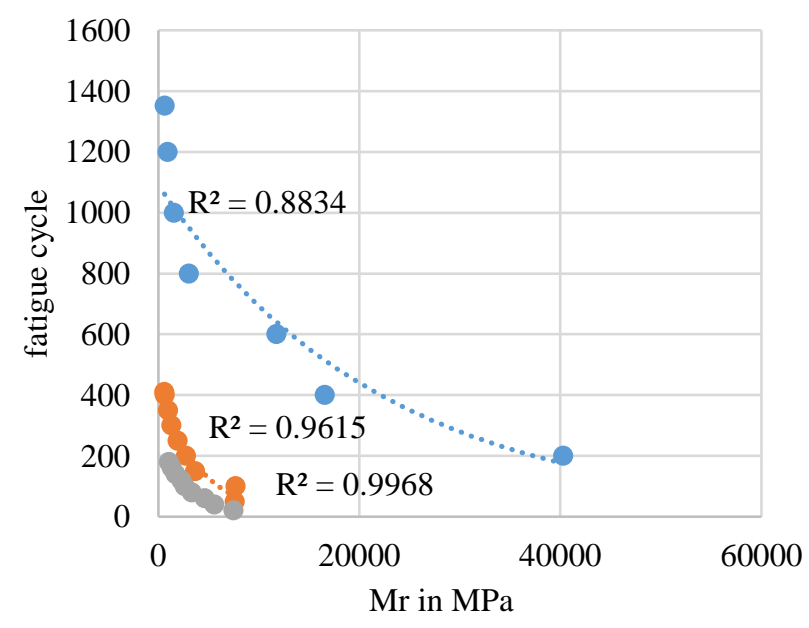

- $10 \%$ stress level $\quad 20 \%$ stress level $\quad 30 \%$ stress level

Fig. 17: Fatigue cycle V/S Mr for $30 \%$ RAP at $45^{\circ} \mathrm{C}$ temperature

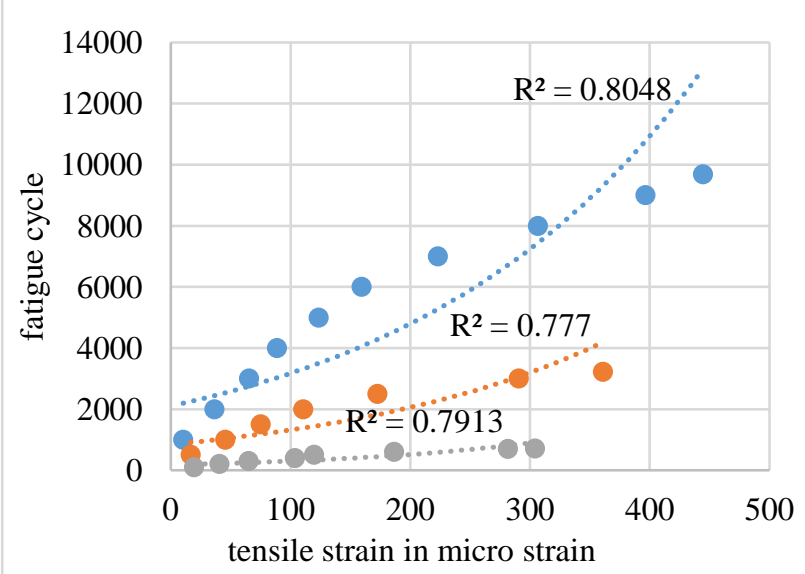

- $10 \%$ stress level $\quad 20 \%$ stress level $\quad 30 \%$ stress level

Fig. 18: Fatigue cycle V/S initial tensile strain for $30 \%$ RAP at $25^{\circ} \mathrm{c}$ temperature

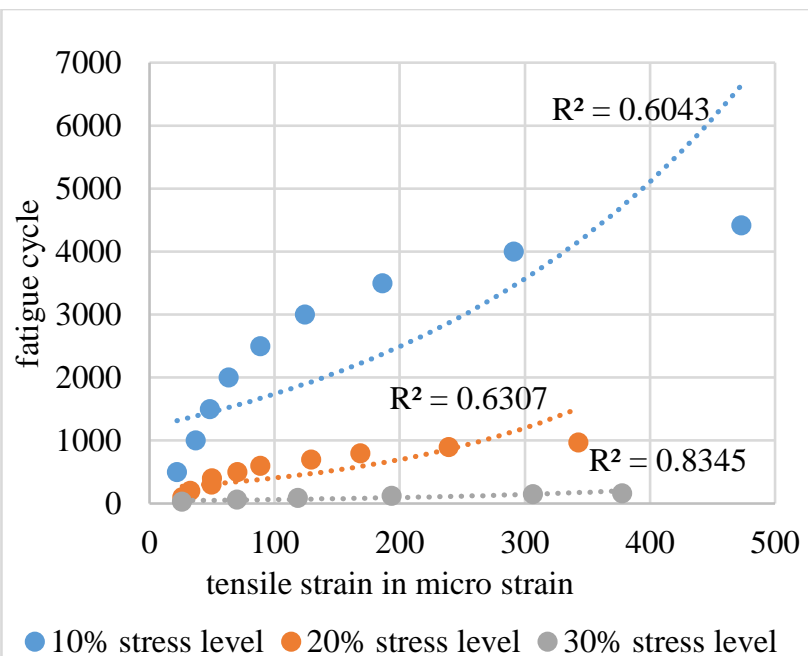

Fig. 19: Fatigue cycle V/S initial tensile strain for $30 \%$ RAP at $35^{\circ} \mathrm{C}$ temperature

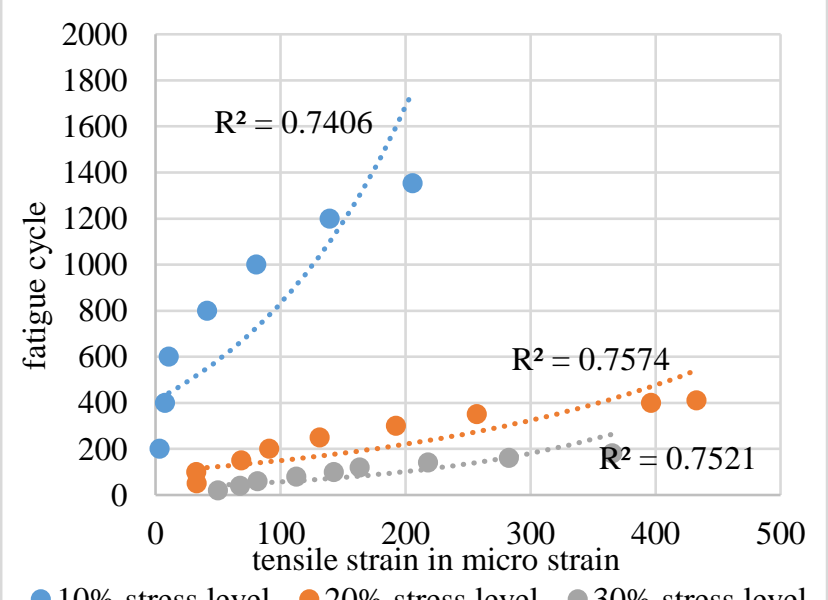

- $10 \%$ stress level $\quad 20 \%$ stress level $\quad 30 \%$ stress level

Fig. 20: Fatigue cycle V/S initial tensile strain for $30 \%$ RAP at $45^{\circ} \mathrm{C}$ temperature

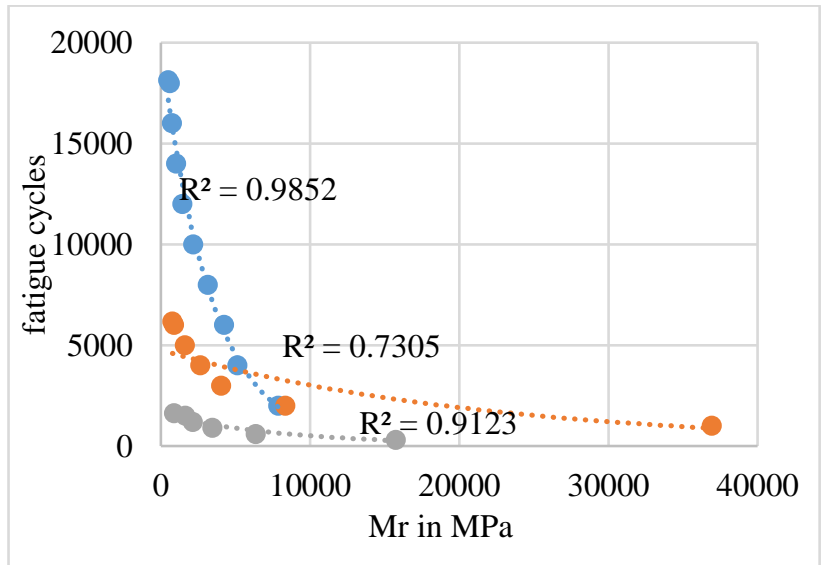

- $10 \%$ stress level $\bullet 20 \%$ stress level $\quad 30 \%$ stress level

Fig. 21: Fatigue cycle V/S Mr for elastomer modified mix at $25^{\circ} \mathrm{c}$ temperature

Published By:

Blue Eyes Intelligence Engineering

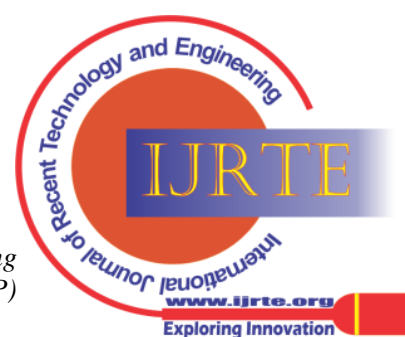




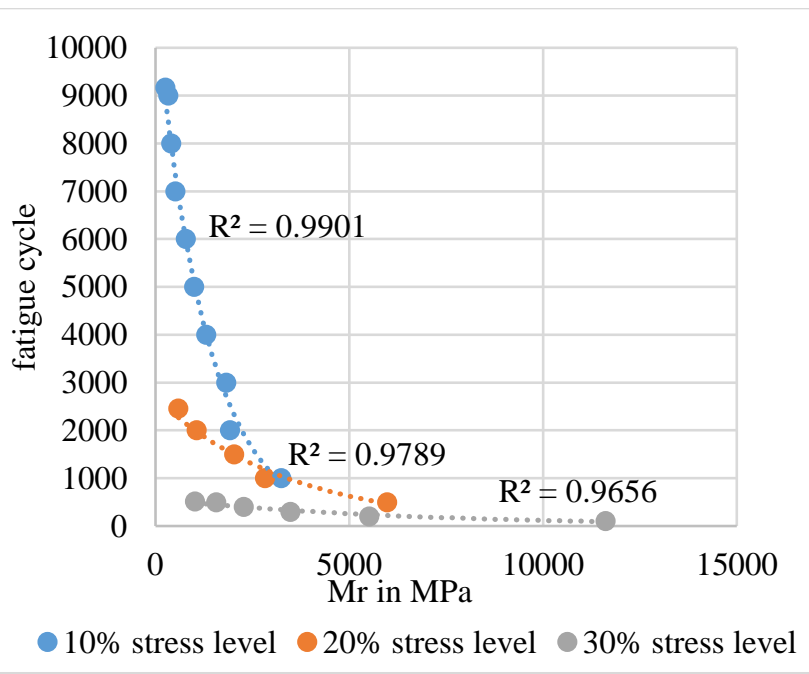

Fig. 22: Fatigue cycle V/S Mr for elastomer modified mix at $35^{\circ} \mathrm{c}$ temperature

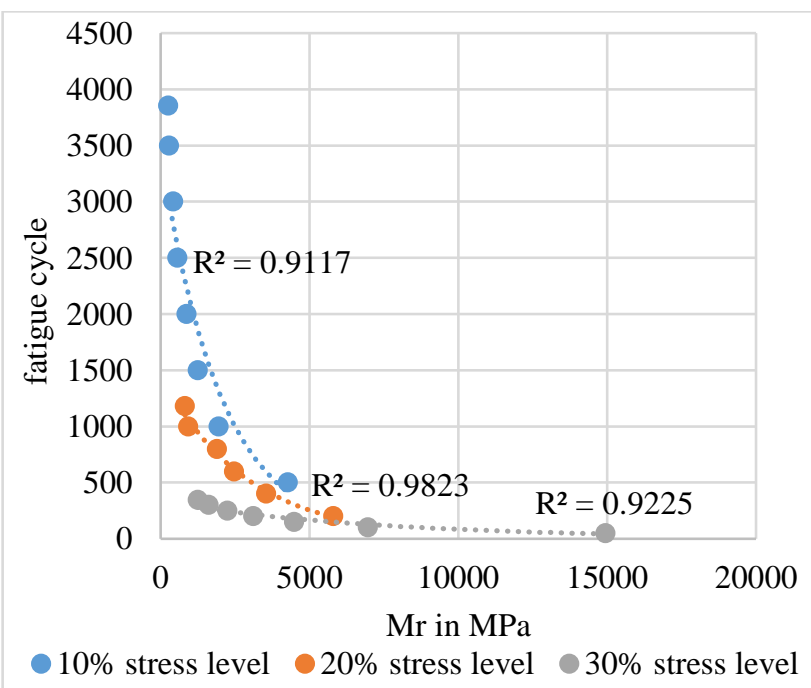

Fig. 23: Fatigue cycle V/S Mr for elastomer modified mix at $45^{\circ} \mathrm{c}$ temperature

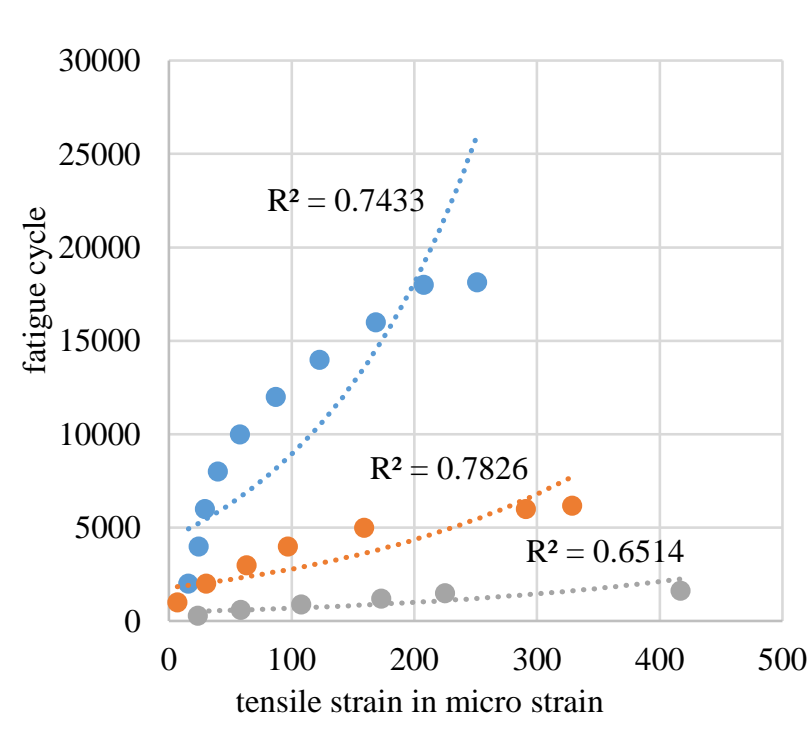

- $10 \%$ stress level $\quad 20 \%$ stress level $\quad 30 \%$ stress level

Fig. 24: Fatigue cycle V/S initial tensile strain for elastomer modified mix at $25^{\circ} \mathrm{c}$ temperature

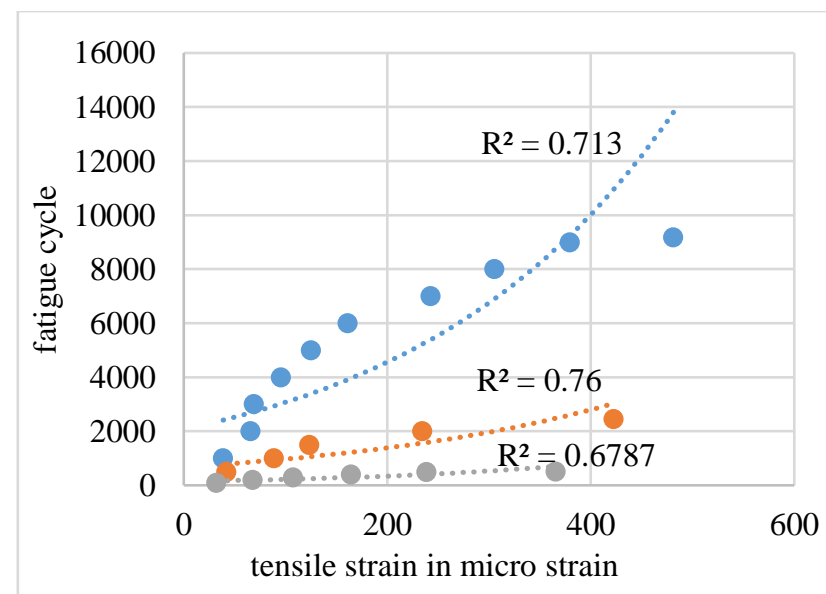

10\% stress level $20 \%$ stress level $30 \%$ stress level

Fig. 25: Fatigue cycle V/S initial tensile strain for elastomer modified mix at $35^{\circ} \mathrm{C}$ temperature

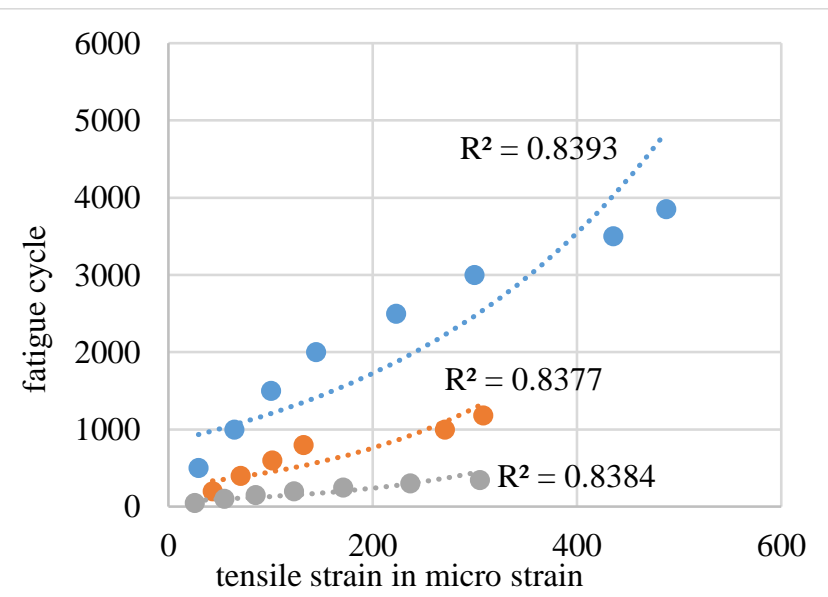

- $10 \%$ stress level $\quad 20 \%$ stress level $\quad 30 \%$ stress level

Fig. 26: Fatigue cycle V/S initial tensile strain for elastomer modified mix at $45^{\circ} \mathrm{C}$ temperature

\section{CONCLUSIONS}

Based on the analysis and discussions, the following conclusions were drawn for the present work

1. Addition of $30 \%$ RAP in SMA mix resulted in increased 1.55 times the stability value of the mix compared to conventional SMA mixes.

2. Addition of elastomer modifier in SMA with $60 \%$ RAP is found to be $60 \%$ and Marshall Properties are within the specified values as prescribed in MoRTH.

3. The drain down test results obtained for conventional SMA mix, 30\% RAP replaced SMA mix and 60\% RAP replaced SMA mix with elastomer modifier of all three types of mixes were found well within the limits i.e. maximum of $0.3 \%$ as prescribed in MoRTH.

4. The indirect tensile strength test results indicated that $60 \%$ RAP replaced SMA mix with elastomer modifier shows highest tensile strength compared to conventional and RAP replaced SMA mixes.
Published By:

Blue Eyes Intelligence Engineering and Sciences Publication (BEIESP) (C) Copyright: All rights reserved.

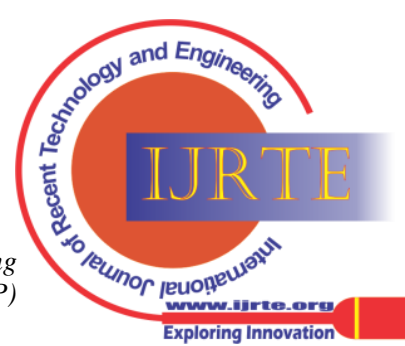




\section{Performance Studies on Stone Mastic Asphalt Mixes with Reclaimed Asphalt Pavement}

5. The Elastomer modified SMA mix offered high resistance to deformation across all stress level.

6. The increase in failure loading resulted in decrease of number of fatigue cycles and increase in the initial tensile strain of the mix.

7. Initial tensile strain decreases with the increased with incorporation of RAP.

8. At $25^{\circ} \mathrm{C}$ temperature for $30 \%$ RAP replacement and $60 \%$ RAP with elastomer modified SMA mix, Fatigue cycles were increased respectively by 1.93 and 3.61 times for $10 \%$ stress level, 2.58 and 4.96 times for $20 \%$ stress level, 2.18 and 4.97 times for $30 \%$ stress level, when compared to conventional SMA mix.

9. At $35^{\circ} \mathrm{C}$ temperature for $30 \%$ RAP replacement and $60 \%$ RAP with elastomer modified mix, Fatigue cycles were increased respectively by 1.79 and 3.72 times for $10 \%$ stress level, 1.57 and 3.9 times for $20 \%$ stress level, 0.56 and 1.8 times for $30 \%$ stress level, when compared to conventional SMA mix.

10. At $45^{\circ} \mathrm{C}$ temperature for $30 \%$ RAP replacement and elastomer modified mix, Fatigue cycles were increased respectively by 0.74 and 2.11 times for $10 \%$ stress level, 1.5 and 4.3 times for $20 \%$ stress level, 1.24 and 2.3 times for $30 \%$ stress level, when compared to conventional mix.

11. As the number of fatigue cycles increases the resilient modulus decreases but initial tensile strain increases.

\section{REFERENCES}

1. IRC, 'Tentative Specifications for Stone Matrix Asphalt', IRC: SP: 79-2008, Indian Road Congress, New Delhi.

2. "SMA MIXTURE WITH MODIFIED ASPHALT AND TREATED AGGREGATES," Goutham Sarang, Lekha B M,Monisha M, Ravi Shankar A U, 2014, pp. 290-299, 2014.

3. Colares, A., Sc, M., Dal, M., Casagrande, T., Ph, D., Soares, J. B., \& $\mathrm{Ph}, \mathrm{D}$. (2014). Behavior of Natural Fiber in Stone Matrix Asphalt Mixtures Using Two Design Methods.26(March), 457-465. https://doi.org/10.1061/(ASCE)MT.1943-5533.0000815.

4. Toth, C. (2015). The effect of VIATOP ${ }^{\circledR}$ plus FEP on the stiffness and low temperature behaviour of hot mix asphalts.January.https://doi.org/10.14382/epitoanyag-jsbcm.2015.20

5. Mishra, B. (2015). A Study on Use of Reclaimed Asphalt Pavement (RAP) Materials in Flexible Pavements. International Journal of Innovative Research in Science, Engineering and Technology (An ISO Certified Organization), 4(12), 12170-12177. https://doi.org/10.15680/IJIRSET.2015.0412088

6. Liphardt, A., Król, J., \& Radziszewski, P. (2016). Influence of Polymer Modified Binder Content from RAP on Stone Mastic Asphalt Rutting Resistance. Procedia Engineering, 153, 407-413. https://doi.org/10.1016/j.proeng.2016.08.142

7. Gubbala Chaitanyaa, Mullapudi Ramya Srib, K. S. R. (2015). Fatigue performance of bituminous mixes containing reclaimed asphal pavement (RAP) material. 3rd Conference of Transportation Research Group of India, December.

8. Awanti, S. S., Amarnath, M. S., \& Veeraragavan, A. (2007). Influence of rest periods on fatigue characteristics of SBS polymer modified bituminous concrete mixtures. International Journal of Pavement Engineering, 8(3), 177-186. https://doi.org/10.1080/10298430601017501

9. Valdes-Vidal, G., Calabi-Floody, A., Sanchez-Alonso, E., \& Miró, R. (2019). Effect of aggregate type on the fatigue durability of asphalt mixtures. Construction and Building Materials, 224, 124-131. https://doi.org/10.1016/j.conbuildmat.2019.07.064

10. Hafeez, I., Kamal, M. A., \& Mirza, M. W. (2015). An experimental study to select aggregate gradation for stone mastic asphalt. Journal of the Chinese Institute of Engineers, Transactions of the Chinese Institute of Engineers,Series A, 38(1), 1-8 https://doi.org/10.1080/02533839.2014.953242

11. Hafeez, I., Kamal, M. A., Mirza, M. W., \& Bilal, S. (2013). Laboratory fatigue performance evaluation of different field laid

asphalt mixtures. Construction and Building Materials, 44, 792-797. https://doi.org/10.1016/j.conbuildmat.2013.03.083

12. Gemechu, M. S. Y. (2018). Study on the Effect of Varying Mixing and Compaction Temperature of BC Mix using Polymer Modified Bitumen. International Journal of Science and Research (IJSR), 7(6), 1649-1655. https://www.ijsr.net/archive/v7i6/ART20183623.pdf

13. GUPTA, S., \& VEERARAGAVAN, A. (2009). Fatigue behaviour of polymer modified $\dagger$ bituminous concrete mixtures. Journal of the Indian Roads Congress, 548, 55-64.

14. Mahrez, A., \& Karim, M. R. (2010). Fatigue characteristics of stone mastic asphalt mix reinforced with fiber glass. International Journal of Physical Sciences, 5(12), 1840-1847.

15. Ganesh, K., \& Prajwal, D. T. (2020). Studies on fatigue performance of modified dense bituminous macadam mix using nano silica as an additive. International Journal of Pavement Research and Technology, 13(1), 75-82. https://doi.org/10.1007/s42947-019-0087-z

16. Ministry of Road Transport \& Highways "Specifications for Road and Bridge works" (Fifth Revision), April 2013

17. IS 73:2013, "Paving Bitumen-Specification (Fourth revision)", Bureau of Indian Standards, 2013, New Delhi, India.

18. S. K. Khanna and C.E.G Justo, "Highway materials and pavement testing laboratory Manual".

19. IRC 37-2018, "Guidelines for the Design of Flexible pavements" (Fourth Revision).

20. American Society for Testing and Materials, Standard test method for indirect tensile test for resilient modulus of bituminous mixtures. ASTM D4123. ASTM International, West Conshohocken, PA, USA, 1995.

\section{AUTHOR'S PROFILE}

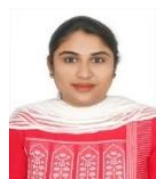

Anusha T M, is currently a Ph.D. Student of BMS College of Engineering in the Department of Civil Engineering, Bangalore-560019. Prior to this her recent appointment was at the PES University as an Assistant Professor in the Department of Civil Engineering. Anusha T M received her Master's degree in Transportation Engineering and Management from Siddaganga Institute of Technology, Karnataka. She also presented various research-based papers in the field of Pavement Materials and Construction at different journals and national and international conferences like At National Conference On Recent Advancements in Geo-technical engineering and At First International Conference on Materials science and manufacturing technology 2019

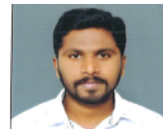

Akhilesh B R is presently working as a Design Engineer in SRC Infra developers Bangalore, Karnataka. Prior to this he worked as Site Engineer for Major district roads in Sira taluk, Tumkur District, Karnataka and also worked as Planning Engineer for National Highway- 75 (NH75), Hassan District, Karnataka. He received his Master' Degree in Transportation Engineering and Management from BMS College of Engineering in the Department of Civil Engineering, Bangalore-560019, Karnataka, India. Akhilesh B R received his Bachelor in Engineering in Civil Engineering in PES College of Engineering, Mandya from Vivesvaraya Technological University, Belgaum, Karnataka, India. He is presently involved construction work such as construction of roads, bridges, buildings and irrigation canals.

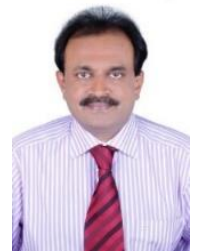

Dr. H S Jagadeesh is currently working as a Professor at the Department of Civil Engineering in BMS College of Engineering, Bangalore-560019. H S Jagadeesh received Doctor in Philosophy (Ph.D.) - Civil Engineering in 2002 and Master's degree in Highway Engineering in 1991 from Bangalore University. He also worked as Dean of placement and Director of International co-operation division for BMS Educational trust for international collaborations. He also published various academic as well as research based papers in the field of Traffic Engineering and Pavement Materials and Construction in several journal like Indian Roads Congress (IRC), Transportation Research Board (TRB), and International Journal of Pavement Engineering Asphalt Technology.

Published By:

Blue Eyes Intelligence Engineering

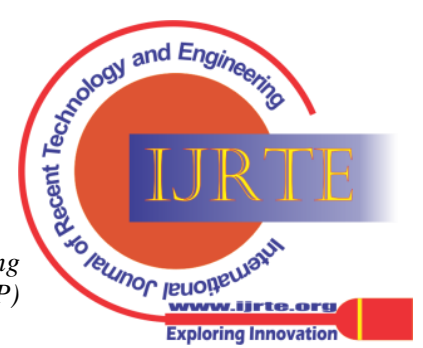

